Fechio, AC, Augusto, CA, \& Nunes, TS. (2020). The effects of homophobia on the work environment: a study in financial institutions in Maringá City/Brazil. Research, Society and Development, 9(7): 1-26, e469974024.

\title{
Os efeitos da homofobia no ambiente laboral: um estudo em instituições financeiras na
} cidade de Maringá/Brasil

The effects of homophobia on the work environment: a study in financial institutions in Maringá City/Brasil

\section{Los efectos de la homofobia no en el lugar de trabajo: un estudio en instituciones} financieras en la ciudad de Maringá/Brasil

Recebido: 27/04/2020 | Revisado: 28/04/2020 | Aceito: 13/05/2020 | Publicado: 23/05/2020

Ana Camila Fechio

ORCID: http://orcid.org/0000-0001-9696-3677

Universidade Estadual de Maringá, Brasil

E-mail: anacamilafechio@gmail.com

Cleiciele Albuquerque Augusto

ORCID: http://orcid.org/0000-0001-5416-3217

Universidade Estadual de Maringá, Brasil

E-mail: cleicielealbuquerque@yahoo.com.br

Thiago Soares Nunes

ORCID: http://orcid.org/0000-0002-1323-8160

Centro Universitário UNA, Brasil

E-mail: adm.thiagosn@gmail.com

\section{Resumo}

$\mathrm{O}$ artigo objetivou identificar os efeitos da homofobia no ambiente laboral de trabalhadores gays em instituições financeiras na cidade de Maringá/PR. Para atingir esses objetivos, dez empregados homoafetivos foram entrevistados individualmente. Os resultados indicaram que os empregados, em sua maioria, consideram suas organizações inclusivas e preocupadas com a diversidade sexual. Foi verificada a ocorrência de heteronormatividade/heterossexismo, sendo que todos os entrevistados relataram ter sofrido com a homofobia em seu ambiente de trabalho, seja de forma direta ou indireta. Ademais, constatou-se que os empregados, em geral, consideram-se satisfeitos com o seu trabalho e concordam que sua satisfação tem relação com sua orientação sexual. Conclui-se que a orientação sexual homoafetiva tem 
impacto na satisfação dos empregados gays nas instituições financeiras investigadas e que, apesar de casos de homofobia, essas instituições têm demonstrado preocupação com a inclusão da diversidade sexual.

Palavras-chave: Heteronormatividade; Homoafetividade; Diversidade sexual; Instituições financeiras.

\begin{abstract}
The article aimed to identify the effects of homophobia on the working environment of gay workers in financial institutions in the city of Maringá/PR. To achieve these objectives, ten homoaffective employees were interviewed individually. The results indicated that employees, for the most part, consider their organizations to be inclusive and concerned with sexual diversity. The occurrence of heteronormativity/heterosexism was verified, and all interviewees reported having suffered from homophobia in their work environment, either directly or indirectly. In addition, it was found that the employees, in general, consider themselves satisfied with their work and agree that their satisfaction is related to their sexual orientation. It is concluded that homoaffective sexual orientation has an impact on the satisfaction of gay employees in the investigated financial institutions and that, despite cases of homophobia, these institutions have shown concern about the inclusion of sexual diversity.
\end{abstract}

Keywords: Heteronormativity; Homoaffective; Sexual diversity; Financial institution.

\title{
Resumen
}

El artículo pretendía identificar los efectos de la homofobia en el entorno laboral de los trabajadores homosexuales en las instituciones financieras de la ciudad de Maringá/PR. Para lograr estos objetivos, se entrevistó individualmente a diez empleados homofafectivos. Los resultados indicaron que la mayoría de los empleados consideran que sus organizaciones son inclusivas y se preocupan por la diversidad sexual. Se verificó la ocurrencia de heteronormatividad/heterosexismo y todos los entrevistados informaron haber sufrido homofobia en su entorno de trabajo, ya sea directa o indirectamente. Además, se encontró que los empleados, en general, se consideran satisfechos con su trabajo y están de acuerdo en que su satisfacción está relacionada con su orientación sexual. Se concluye que la orientación sexual homosexual tiene un impacto en la satisfacción de los empleados homosexuales en las instituciones financieras investigadas y que, a pesar de los casos de homofobia, estas instituciones han mostrado preocupación por la inclusión de la diversidad sexual. 
Palabras clave: Heteronormatividad; Homo-afectividad; Diversidad sexual; Instituciones financieras.

\section{Introdução}

A diversidade no ambiente de trabalho é cada vez mais evidenciada, uma vez que, no corpo de empregados de uma empresa, existem pessoas de diferentes características e particularidades. Em decorrência disso, a diversidade tornou-se um fator que precisa ser estudado pelas organizações para que essas possam usar as diferenças de cada empregado para potencializar o alcance dos seus objetivos. Por outro lado, a diversidade também precisa ser compreendida pelos empregados para que todos possam respeitar as suas diferenças, colaborando para a satisfação dos mesmos dentro do ambiente de trabalho.

Várias temáticas têm sido associadas a diversidade, envolvendo questões relacionadas a orientação sexual, raça, gênero, etnia, entre outros fatores. O foco de discussão deste estudo recai sobre a diversidade sexual, especificamente a orientação sexual homoafetiva, por ser um dos grupos considerados mais marginalizados dentro de uma empresa (Siqueira \& Fellows, 2006). Essa marginalização pode ser consequência do heterossexismo e da heteronormatividade.

Entende-se por heterossexismo uma forma negativa de tratar as pessoas baseada na sua orientação sexual, usando de tratamentos segregacionistas e, muitas vezes, se assemelhando, e até mesmo se confundindo, com comportamentos homofóbicos (Borillo, 2010). Logo, o heterossexismo é uma forma de preconceito que afeta os indivíduos da sociedade que não se identificam como sendo heterossexuais.

A heteronormatividade é compreendida como a forma de colocar a heterossexualidade como sendo uma orientação sexual natural, ou seja, aqueles que não se identificam dentro desse grupo são considerados como desviados e, até mesmo, pecadores (Seffner, 2013). A heteronormatividade estabelece uma norma onde o papel do homem e da mulher são complementares e a única forma normal de relacionamento é a do homem desejando uma mulher e vice-versa (Carvalho, 2004). Esse tipo de pensamento pode alienar a sociedade a um pensamento discriminatório e segregacionista.

O heterossexismo e a heteronormatividade podem contribuir para a ocorrência da homofobia. A homofobia é conceituada como um fenômeno social que envolve a discriminação, preconceito e violência contra qualquer pessoa que demonstra um comportamento diferente daquele ditado pela heteronormatividade (Junqueira, 2007). Esse 
tema tem sido discutido nas mídias, nas escolas, nas universidades, entre outros, com o objetivo de conscientizar as pessoas de que, não apenas em relação a homoafetivos, mas em todos os tipos possíveis de relação, nenhum tipo de agressão, seja ela física ou emocional, deve ser tolerada.

No ambiente de trabalho, questões envolvendo a diversidade sexual, e seus aspectos decorrentes, tais como o heterossexismo, heteronormatividade e homofobia, podem ter impacto direto na satisfação dos funcionários homoafetivos. A satisfação pode ser definida como sendo um montante de sentimentos positivos nutridos pelo empregado em relação ao seu trabalho (Davis \& Newstrom, 2001). Assim, a existência de heteronormatividade, heterossexismo e homofobia podem gerar sentimentos negativos no empregado homoafetivo, o que, consequentemente, poderia culminar em sua insatisfação e afetar negativamente o seu desempenho dentro da organização.

Siqueira e Fellows (2006) afirmam que dos grupos mais marginalizados dentro das empresas estão o dos gays e o das lésbicas por terem, muitas vezes, seus direitos negados e por ser motivo de piadas e discriminação em seu dia a dia. As instituições financeiras podem ser consideradas em sua essência como empresas mais conservadoras e tradicionais. Por outro lado, observa-se cada vez mais a inclusão de trabalhadores homoafetivos assumidos em todos os âmbitos de atividade, incluindo instituições financeiras (Siqueira \& Fellows, 2006).

Diante disso, o objetivo geral desse trabalho é identificar os efeitos da homofobia no ambiente laboral de trabalhadores gays em instituições financeiras na cidade de Maringá/PR. Para atender esse objetivo, desenvolveram-se as seguintes etapas: a) descrever o entendimento dos entrevistados sobre a questão da diversidade sexual dentro das instituições financeiras; $b$ ) identificar a ocorrência de heteronormatividade/heterossexismo e se ela contribui para a ocorrência de casos de homofobia; c) averiguar se os funcionários homossexuais estão satisfeitos dentro das instituições financeiras.

A presente pesquisa justifica-se não apenas teoricamente, pela falta de pesquisas e artigos relacionados à diversidade sexual, mas também se justifica empiricamente, pelo fato do preconceito estar impactando vidas negativamente em diversos ambientes sociais, incluindo o das empresas.

É preciso desenvolver trabalhos relacionados a temática a fim de promover conscientização, considerando que empregados gays são também peça chave para o desempenho positivo das organizações e, por isso, é necessário que se tenha preocupação com a sua satisfação no ambiente de trabalho. 


\section{Revisão da Literatura}

Esta seção propõe-se a discutir, por meio de referências bibliográficas, a diversidade sexual dentro das organizações, heteronormatividade/heterossexismo, homofobia e satisfação, respectivamente. Inicialmente serão apresentadas formas com as quais a diversidade se mostra nas instituições por meio de seus empregados, impactos em se preocupar com a gestão dessas diversidades e um pouco sobre a diversidade sexual nesses contextos. No tópico de Heteronormatividade/Heterossexismo encontramos definições sociais de ambas, bem como suas diferenças e implicações.

Sobre homofobia, trazemos além de conceitos, tipos de violências consideradas homofobia e como ela se apresenta no ambiente de trabalho. Sobre satisfação trataremos as definições de satisfação e insatisfação, fatores que colaboram para a sua ocorrência e impactos dessa satisfação nas organizações.

\subsection{Diversidade sexual dentro das organizações}

A diversidade tem sido um tema debatido nas organizações, pois, notou-se a existência de pessoas com diferentes características dentro de uma mesma empresa, formando assim um ambiente heterogêneo de trabalho. Para Alves e Galeão-Silva (2004), a diversidade refere-se a uma variedade de atributos de indivíduos e grupos. Para Irigaray e Freitas (2011), a heterogeneidade tornou-se um desafio tanto para os empregados quanto para as empresas.

Moraes (2004) traz um panorama acerca da inserção dos indivíduos no ambiente organizacional e como se chega a ocorrência da diversidade: Quando o indivíduo ingressa na empresa, ele leva consigo uma série de condutas, pensamentos e posturas que, em muitos casos, divergem das ações da empresa (missão, valores e cultura), tornando estes uns dos pontos para a diversidade dentro do ambiente de trabalho.

Outra contribuição de Moraes (2004) é a constatação da forma com que essas diversidades se apresentam dentro da organização, geralmente acontecendo nas áreas que possibilitam ocorrência de estreitamento dos relacionamentos internos, entre áreas, intra áreas e nos grupos de trabalho. A corroborar com esse autor, temos Hanashiro e Carvalho (2005, p. 5) que nos trazem que

[...] a teoria de relações intergrupais que reconhece que os indivíduos não abandonam suas identidades raciais, sexuais ou étnicas quando entram em uma organização [...]. 
Mas, a identidade das pessoas nas organizações é formada pela filiação ao grupo de identidade e ao grupo organizacional. Por essa ótica teórica as organizações tentam administrar os conflitos potenciais que surgem da interação entre os grupos de identidade e grupos organizacionais.

Segundo Torres \& Pérez Nebra (2004), a consideração da diversidade nas organizações significa a inclusão de todos os empregados, independentemente de suas diferenças, etnia, raça, gênero, orientação sexual, idade, entre outros. A partir da inclusão, é possível evidenciar as diferenças e semelhanças dos empregados e canalizar essas características para contribuir para o desempenho organizacional, motivação e satisfação dos empregados.

Hanashiro \& Carvalho (2005) destacam como benefícios da diversidade o incentivo a criatividade, troca de experiências e maior flexibilidade no processo decisório. Por outro lado, os autores apontam que existem desvantagens e riscos, como possíveis custos para se recrutar e conservar uma equipe diversificada, a elevação de rotatividade, conflitos interpessoais e problemas de comunicação.

Com o objetivo de fazer a gestão das relações de trabalho e da composição do corpo de empregados, Fleury (2000) afirma que surge a gestão da diversidade em uma organização. Para Thomas (1990), a gestão da diversidade é um conjunto de práticas administrativas que tem como finalidade a adoção da subjetividade de cada indivíduo ou particularidades de um grupo como recursos que potencializem o desempenho da organização.

A diversidade sexual, foco desta pesquisa, abrange pessoas de diferentes orientações sexuais, homoafetivos, bissexuais, heterossexuais, entre outros. Assim, pode-se dizer que a gestão da diversidade sexual é o esforço que as empresas canalizam para direcionar as particularidades dos empregados, independente de sua orientação sexual (gay, lésbicas, bissexual, entre outros), de forma a alavancar o desempenho empresarial.

Historicamente, apenas em 1970 surgiram grupos interessados na defesa das causas homossexuais. Facchini (2005) afirma que o movimento tinha ideais da contracultura e visavam não apenas à aceitação da homoafetividade, mas também à mudança no modo como a sexualidade era vivenciada. A homoafetividade assumiria, então, um papel transformador da cultura heteronormativa (Freire \& Cardinali, 2012)

Em contextos sociais complexos, um dos desafios necessários é deslocar-se dos binarismos rígidos e cristalizados de masculino/feminino, de opressão/submissão (Nascimento, 2011). Scott (1995) propõe que desconstruir essa polaridade significa problematizar tanto a oposição entre os polos, como a unidade interna de cada um. Significa 
observá-los como fragmentados e divididos, com suas coerências e seus paradoxos, sendo a própria polaridade construída e não uma entidade fixa dada. Como afirma Louro (2004), existem serias consequências a partir da desconstrução da oposição binária que a masculinidade e a feminilidade se apresentam socialmente.

Siqueira \& Fellows (2006) afirmam que um dos grupos mais marginalizados dentro das empresas é o dos gays e o das lésbicas por terem, muitas vezes, seus direitos negados e por serem motivo de piadas e discriminação em seu dia a dia. Entendendo que os homoafetivos formam um dos grupos que mais sofrem dentro das organizações foi necessário discuti-los de forma aprofundada no tópico subsequente.

\subsection{Heteronormatividade/Heterossexismo}

A heteronormatividade e o heterossexismo são conceitos que necessitam ser esclarecidos para maior entendimento desse artigo. Borillo (2010, p. 20), define o heterossexismo relacionado a heteronormatividade como:

O sistema a partir do qual uma sociedade organiza um tratamento segregacionista segundo a orientação sexual pode ser denominado "heterossexismo". Ele e a homofobia - compreendida como a consequência psicológica de uma representação social que, outorgando à heterossexualidade o monopólio da normalidade, fomenta o desdém em relação àqueles e àquelas que se distanciam do modelo de referência.

Segundo assim, a heteronormatividade é o que coloca a heterossexualidade de forma superior a qualquer outra orientação, sendo um conceito que foi formado pela sociedade e oprime aqueles que escolhem uma sexualidade diferente da "normal", que seria a heterossexualidade.

O heterossexismo, segundo Herek (1992) pode ser compreendido como um sistema ideológico que nega, denigre e estigmatiza qualquer forma não heterossexual de comportamento, identidade, relacionamento ou comunidade. Souza e Pereira (2013) afirmam que esse mesmo o sistema ideológico produz privilégios para pessoas que seguem as normas heterossexuais e exclui aquelas que não as seguem. Esses privilégios incluem direitos civis para casamentos entre heterossexuais, tratamento social não estigmatizado em razão de sua sexualidade, entre outros.

Com o objetivo de estudar o heterossexismo no ambiente de trabalho, Smith e Ingram (2004) desenvolveram uma pesquisa onde eles concluíram que o heterossexismo no ambiente 
(CC BY 4.0) | ISSN 2525-3409 | DOI: http://dx.doi.org/10.33448/rsd-v9i7.4024

de trabalho está grandemente relacionado com a ocorrência depressão e os distúrbios psicológicos dos sujeitos pesquisados. Sobre essa relação, destaca-se o estudo de Chauí (1984) sobre a repressão sexual. Através da pesquisa em dicionários acerca de diversos significados da palavra repressão, o autor conclui que ela não se impõe apenas de maneira exterior a aquilo que somos. Ele conclui também ocorrer através da interiorização de proibições e interdições - até permissões - externas que se convertem em internas. Essas permissões internas "são vividas por nós sob a forma do desagrado, da inconveniência, da vergonha, do sofrimento e da dor" (Chauí, 1984, p. 13).

Para Alves e Galeão-Silva (2004), ao considerarem que sexo e gênero não se dissociam, descrevem ambos como construções sociais que se materializam a partir de normas regulatórias da hegemonia heterossexual.

Eles apontam a diferença sexual dos corpos, como um fenômeno que se configuram desde o nascimento dos indivíduos, sendo necessárias constantes reafirmações de normas morais, abrindo possibilidades para a própria descaracterização normativa da heterossexualidade.

Portanto, as normas regulatórias do 'sexo' trabalham de uma forma performativa para constituir a materialidade dos corpos e, mais especificamente, para materializar o sexo do corpo e, para materializar a diferença sexual a serviço da consolidação do imperativo heterossexual (Butler, 2008).

Ainda, segundo Butler (2008), determinadas rotulações, diferenciações e classificações são consequências da norma regulatória que age com o poder de marcar os corpos.

Com isso, institui-se a materialização do sexo e da mais força a heteronormatividade dentro da cultura da sociedade atual, já que essas citações são constantemente recuperadas e reiteradas ao longo da trajetória do indivíduo, moldando, engendrando o que é masculino e feminino dentro dos padrões da heterossexualidade.

A essa constante reafirmação da norma heteronormativa, Butler (2008) propõe o conceito de citacionalidade, ou seja, quanto mais se repetem esses discursos, mais naturalizada e normativa se torna a heterossexualidade.

Assim, "para se qualificar e permanecer como um sujeito viável, dentro da normatividade, e não um sujeito abjeto, o indivíduo é obrigado a citar a heteronormatividade durante toda a vida" (Butler, 2008, p. 98). E é essa forma discriminatória de pensar que dá origem a homofobia. 


\subsubsection{Homofobia e sua ocorrência no ambiente de trabalho}

A homofobia é um tema que tem sido muito debatido nas mídias e por todos os lugares. Tornou-se motivo de preocupação por sua intolerância e também motivo para despertar a conscientização para que as pessoas não enxerguem na orientação sexual uma razão para gerar violência, agressividade, assédio, ou qualquer outro tipo de desrespeito a qualquer indivíduo.

Em sua discussão sobre o fenômeno da homofobia, Junqueira (2007) o caracteriza como um fenômeno social associado a preconceitos e até a casos de violência contra qualquer um ou quaisquer coisas (situações ou até uma simples relação com o estilo de vida homossexual) que se destoem da heteronormatividade. Welzer (2001) reforça o conceito ao propor a homofobia como a discriminação contra indivíduos que mostram, ou a quem se atribui, algumas qualidades (ou defeitos) características de outro gênero, com isso, engessando essas fronteiras.

No que se refere a ocorrência da homofobia nas empresas, Bicalho (2008, p. 12) indica um conceito da forma com que se percebe esse tipo de violência: "[...] ato de agredir o sujeito física ou discursivamente em seu ambiente de trabalho, impactando de modo degradante em questões atinentes ao seu trabalho, à sua vida pessoal e às suas relações; com destaque para as implicações psicopatológicas”. Siqueira, Saraiva, Carrieri, Lima e Andrade (2009, p. 449) traçam um paralelo entre a homofobia e outras formas de violência contra os indivíduos e alguns desdobramentos dessas agressões dentro das organizações:

Associada ao machismo, à baixa escolaridade e à impunidade, a homofobia se reproduz em diversas esferas sociais, provocando a estigmatização do indivíduo gay. No meio organizacional, a situação não é diferente, sendo observadas distintas formas de discriminação do diferente e de recusa do outro, o que se estende aos homossexuais, que se veem muitas vezes desamparados em situações de preconceito e atos discriminatórios, velados ou explícitos, em que são limitadas as possibilidades de ascensão profissional, de relacionamentos sociais, e de inserção mais ampla nas organizações.

Segundo Bainha \& Silva (2016), uma das vertentes da homofobia nas organizações pode ser apontada como o bullying homofóbico. O bullying ou assédio moral, pode ser caracterizado como qualquer conduta abusiva (gestos, comportamentos, palavras e atitudes), repetidas e sistemáticas, dirigidas a um ou mais indivíduos, que pode provocar danos à 
dignidade ou integridade física e/ou psíquica do individual, afetar seu trabalho e o clima laboral (Hirigoyen, 2006).

Croteau (1996) observa que o medo de sofrer esse tipo de violência é um dos principais fatores vivenciados pelos homossexuais no ambiente de trabalho. Esta vivência emocional dolorosa pode, em alguns casos, como alerta Dourlen (2005, p. 85), atingir a representação (consciente e inconsciente) "que o indivíduo possui de si mesmo". A tensão oriunda dessas práticas insere o indivíduo em um estado de confusão e de sofrimento que, não raras vezes, culminam em seu adoecimento, por mais que utilize estratégias de defesa na manutenção da sua normalidade psíquica (Siqueira et al., 2009).

Por ser minoria dentro da sociedade e das organizações, os homossexuais encontram limitações dentro das empresas em que estão inseridos (Siqueira \& Fellows, 2006). Estes autores completam que a homoafetividade constatada (ou admitida) é tema constante de piadas e de desprezo no contexto organizacional onde, consequentemente, o gay assumido é vítima de diversos tipos de violência e boicotes, especialmente quando ocupa posições altas dentro da hierarquia de cargos. Percebe-se, portanto, que a homofobia é algo negativo, gera discriminação e consequente insatisfação para aqueles que são afetados por essa prática.

\subsection{Satisfação}

Locke (1969), a satisfação no trabalho é resultado da avaliação do próprio empregado sobre o seu trabalho, o que gera uma emoção positiva de bem-estar. Ao contrário disso, Locke (1969) afirma que temos a insatisfação, quando a avaliação envolvendo o trabalho desenvolvido pelo trabalhador gera no mesmo um sentimento não positivo, o de desprazer e sofrimento. Fraser (1983) afirma que o tema satisfação no trabalho é complexo e de difícil definição, pois decorre de um estado subjetivo em que o acontecimento que provocou este sentimento varia de pessoa a pessoa. Sendo que o mesmo evento pode ter reação diferente ao longo do tempo e estar sujeito a influências internas e externas ao ambiente laboral.

Para Rego (2001), a satisfação no trabalho está relacionada ao tratamento de Justiça e de respeito a que o trabalhador é submetido. Já Robbins (2002), nos traz uma definição de satisfação no trabalho defendendo que o empregado tem uma reação não passiva quando vivencia situações que o deixa insatisfeito. Dessa forma o autor conceitua a satisfação no trabalho como uma atitude geral do trabalhador em relação ao trabalho que ele faz.

Fraser (1983) apresenta a satisfação no trabalho como um estado pessoal, subjetivo, dinâmico e constantemente modificável por condições intrínsecas e extrínsecas do trabalho e 
do trabalhador. Para Estefano (1996), os fatores considerados como os mais significantes ao estresse e à insatisfação no trabalho são a falta de conhecimento sobre oportunidades de progresso e promoção no trabalho e o modo como ocorre a avaliação da performance profissional. Outros fatores são a carga de trabalho excessiva, a interferência do trabalho na vida particular, a carência de autoridade e influência necessárias à execução de seu trabalho.

Em estudo realizado por Ibid (1996) sobre a satisfação dos funcionários (total de 88) da biblioteca central da Universidade Federal de Santa Catarina, verificou-se que o principal fator responsável pela insatisfação desses funcionários constitui-se nas condições de trabalho, sendo que os aspectos que mais contribuíram para a satisfação foram às relações interpessoais e o trabalho em si.

Dentre as várias opiniões de diversos autores, o ponto central de consenso de todos eles e o fato de cada indivíduo realizar avaliação dos aspectos que compõem o ambiente organizacional em sua totalidade, ou seja, chegar a uma avaliação positiva leva o indivíduo a considerar-se satisfeito, ao passo que chegar a uma avaliação negativa desse ambiente, leva a insatisfação.

Como consequência da satisfação no trabalho podemos destacar diversos benefícios para os empregados, como: aumento na qualidade de vida do trabalhador, aumento na qualidade da saúde dos empregados, aumento na realização pessoal do indivíduo, dentre outros, conforme apontam Paraguay \& Martinez (2003).

Ao mesmo tempo em que se detectam benefícios individuais para os empregados, percebe-se que, por gerar benefícios para o indivíduo, como consequência percebe-se benefícios para a empresa, como: diminuição nas faltas, diminuição nos afastamentos por atestados, diminuição de greves e protestos, e o aumento na produtividade do indivíduo dentro das organizações (Ibidem, 2003).

\section{Metodologia}

Pesquisas são realizadas para se alcançar novos conhecimentos para a sociedade como afirmam Pereira et al. (2018). A presente pesquisa apresentou uma abordagem qualitativa, a qual pauta seus estudos na interpretação do mundo real, preocupando-se com o caráter hermenêutico na tarefa de pesquisar sobre as vivências dos indivíduos (Oliveira, 2008). No caso desta pesquisa, foram analisadas vivências dos empregados homossexuais, dentro da amostragem selecionada, por conta da sua orientação sexual. 
Ademais, pode ser classificada como descritiva e explicativa. Segundo Gil (1999), a pesquisa descritiva é aquela que pretende expor as características de determinado grupo estabelecendo relações entre diversas variáveis. No presente artigo foram descritas as particularidades encontradas dentro do grupo dos homens gays, levando em consideração sua satisfação no ambiente de trabalho. Por sua vez, a pesquisa explicativa, segundo o autor, identifica os fatores que são responsáveis pelo acontecimento de determinado fator. Esse fator, no caso do artigo, foi a geração da satisfação ou insatisfação a partir de situações ocorridas por consequência da orientação sexual gay do empregado.

O público alvo da pesquisa foram os empregados (homens homoafetivos) de instituições financeiras na cidade de Maringá, no estado do Paraná. Logo, a divulgação ocorreu pelas redes sociais, in loco, e também pela técnica de pesquisa snow ball. Esta técnica, não probabilística, na medida em que os participantes iniciais da pesquisa participam da mesma, os mesmos indicam outros novos participantes e assim sucessivamente; ocorrendo até que novos entrevistados passam a repetir os conteúdos sem acrescentar novas informações relevantes ("ponto de saturação") (Baldin \& Munhoz, 2011). Portanto, foram realizadas 10 entrevistas.

Os dados foram coletados por meio de entrevistas com os participantes, utilizando um roteiro semi-estruturado. Para Ribeiro (2008), a entrevista pode ser definida como uma forma de obter informações a respeito de uma amostra em analise que vá além do texto, ou seja, informações subjetivas como sentimentos e valores, permitindo que mais de uma fonte de interpretação seja aplicada na análise de resultados dos entrevistados.

O roteiro semiestruturado dividiu-se em quatro partes: 1) descrição do perfil pessoal e profissional; 2) relato de experiências vividas dentro de instituições financeiras envolvendo a sua orientação sexual e seu entendimento sobre a questão da diversidade sexual nessas instituições; 3) Relato de situações e casos de heteronormatividade/heterossexismo ocorridos na instituição que se desdobraram ou não em situações de homofobia; 4) Verificação se os colabores homoafetivos se encontram satisfeitos nas instituições e se isso tem relação com a sua orientação sexual.

Quanto aos procedimentos de análise dos dados, foi utilizada a análise de conteúdo de Bardin (2011) para explorar o material das entrevistas, filtra-los e realizar a inferência e interpretação do conteúdo das mensagens apresentadas pelos entrevistados.

A Figura 1 seguinte, apresenta o esquema de um fluxograma que apresenta a sequencia de trabalho. 
Research, Society and Development, v. 9, n. 7, e469974024, 2020

(CC BY 4.0) | ISSN 2525-3409 | DOI: http://dx.doi.org/10.33448/rsd-v9i7.4024

Figura 1 - Esquema de análise do trabalho.

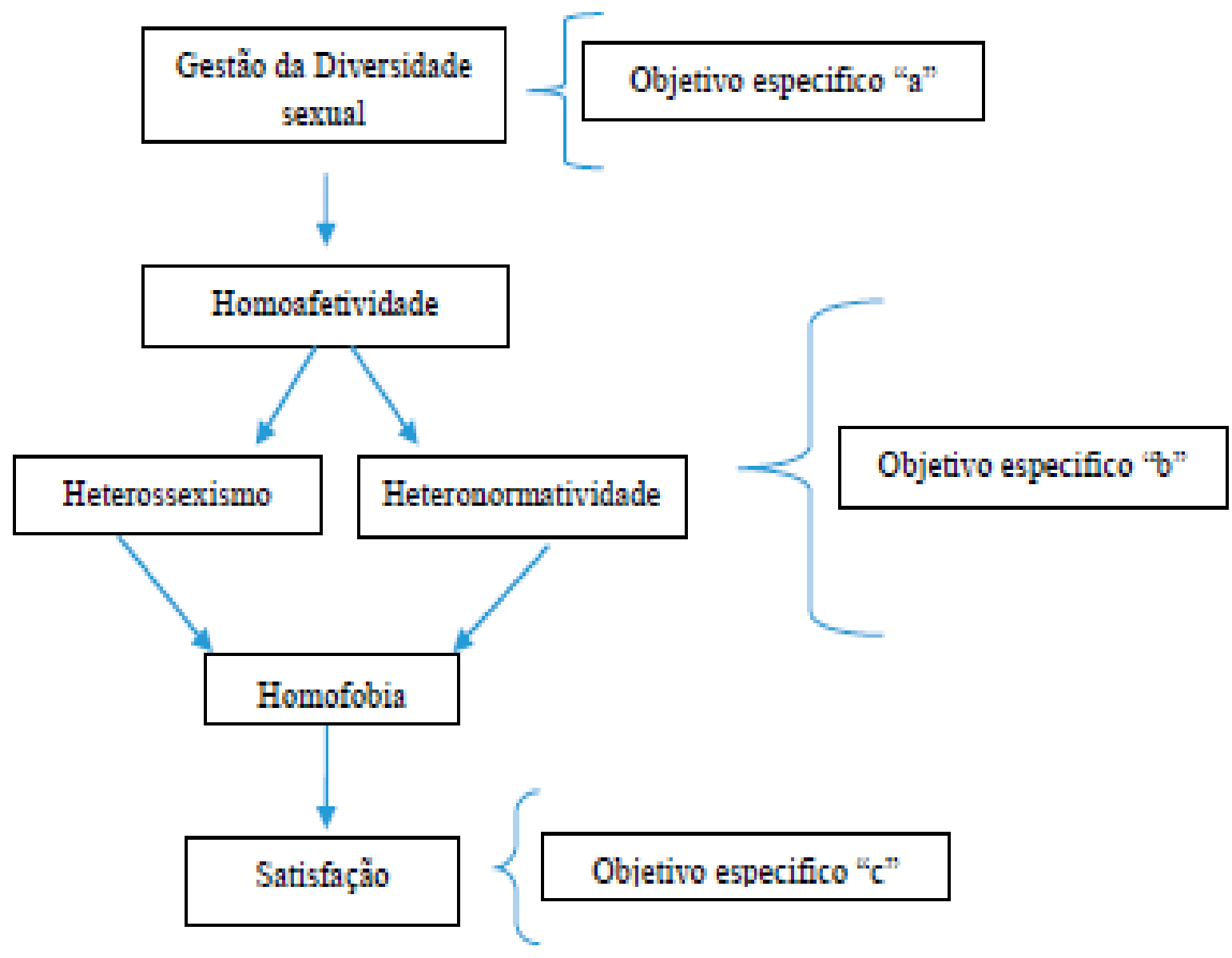

Fonte: Autores.

Para ilustrar a análise realizada no trabalho, foi desenvolvida a Figura 1. Nela, consideramos a diversidade sexual como assunto principal proposto, e a gestão da diversidade sexual como tema relevante. Identificaram-se dois possíveis fatores impactantes para esse grupo dentro de seu ambiente de trabalho - heteronormatividade e heterossexismo.

Após breve estudo, constatou-se que ambos os fatores levam a ocorrência de casos de homofobia e, a partir disso, buscou-se compreender a relação entre essas ocorrências e a constatação de satisfação dentro do ambiente de trabalho dos sujeitos homossexuais entrevistados.

Enfatiza-se que esta pesquisa se limita a uma pequena amostra de empregados homossexuais de instituições financeiras. Também vale destacar que o processo de seleção de entrevistados - snow ball - não permitiu que nenhum empregado de instituição bancaria pública fosse entrevistado, assim, a pesquisa se restringiu ao setor financeiro privado. 


\section{Resultados e Discussão}

Esta seção apresenta o perfil dos participantes, e na sequência, em cada subseção, a análise dos resultados obtidos na pesquisa respondendo aos objetivos definidos na pesquisa.

\subsection{Perfil dos participantes}

A presente pesquisa buscou analisar a população dos homens homoafetivos, tendo como amostra e objeto de estudo os homens homoafetivos que trabalhem em instituições financeiras localizadas na cidade de Maringá.

Os sujeitos apresentados compõem um grupo de 10 homens, de 22 a 35 anos, todos empregados de 3 instituições financeiras privadas, sendo 4 agências e 2 unidades administrativas. O grau de escolaridade dos participantes foram: superior incompleto (2), superior completo (6) e pós-graduação/especialização (2). Percebe-se, portanto, que se trata de um grupo jovem com preocupação com desenvolvimento intelectual.

Dos 10 empregados entrevistados, todos estão em cargos operacionais, com níveis no organograma que variam de estagiário a gerente, conforme ilustrado no Quadro 1.

Tabela 1 - Panorama de instituições e cargos da amostra.

\begin{tabular}{cll}
\hline Entrevistados & \multicolumn{1}{c}{ Instituição } & \multicolumn{1}{c}{ Cargo } \\
\hline 1 & Itaú & Caixa \\
2 & Itaú & Assistente de gerente \\
3 & Sicoob Metropolitano & Gerente de relacionamento \\
4 & Sicoob Central & Analista de comunicação \\
5 & Sicoob Central & Analista de gestão de pessoas \\
6 & Sicoob Metopolitano & Assistente de suporte operacional \\
7 & Itaú & Estagiário Comercial \\
8 & Sicoob Central & Assistente de comunicação \\
9 & Sicoob Central & Analista de credito \\
10 & Sicoob Metropolitano & Assistente de agência \\
\hline
\end{tabular}

Fonte: Autores.

Dentre as áreas de atuação dentro da instituição, identificaram-se 2 empregados da área de comunicação, 1 da área de recursos humanos, 2 que exercem funções administrativas, como analista de crédito e assistente de suporte organizacional, e os demais estão em funções de interação com clientes, como atendimento/comercial e caixa. 
Todos os entrevistados já contam com carreira profissional de, no mínimo, 2 instituições, ou seja, já conhecem diferentes realidades de mercado. Consequentemente, diferentes culturas organizacionais que lhes serviram de base para a análise da instituição a qual pertencem no presente. Apenas o entrevistado 9 já possuía experiência em instituição financeira - estágio no Banco do Brasil; os demais estão em seu primeiro contato com esse tipo de empresa.

Um ponto positivo da amostra foi a receptividade com que a pesquisa foi recebida. Durante todas as entrevistas obtivemos muita disposição dos entrevistados seja em responder da maneira mais completa e rica de detalhes possível, seja indicando outros entrevistados. $\mathrm{Ou}$ seja, existiu uma carga de emoção em todos eles por conta do sofrimento, resistência e preconceito que essa situação proporciona para cada um deles, porém em nenhum momento foi identificado qualquer sinal de autocomiseração. Foi percebido um alto grau de maturidade emocional para o relato das experiências, além de todos destacarem a relevância que esse tipo de pesquisa tem para eles.

Os entrevistados foram questionados com relação a serem assumidos ou manterem sua sexualidade em sigilo. Dos entrevistados, 6 responderam serem assumidos desde o primeiro dia na instituição, enquanto outros 4 afirmaram não assumir, porém, caso sejam abordados, não negam e revelam sua sexualidade. O entrevistado 3 traz a seguinte percepção sobre não assumir inicialmente: “[...] Acho que todos devemos respeitar o direito do outro. Caso ele não queira saber, ele não vai perguntar e eu não preciso impor isso, por isso fico na minha e só assumo quando perguntam".

Com relação a assumir ou não a homossexualidade, de todos os entrevistados, apenas o entrevistado 1 informou ser assumido apenas para amigos próximos em quem confia e no ambiente de trabalho, ou seja, não é assumido fora da empresa por causa dos pais, que não aceitam que o mesmo seja homoafetivo.

\subsection{A diversidade sexual dentro das instituições financeiras}

Todos os empregados entrevistados reconheceram suas instituições como preocupadas em manter um clima organizacional favorável a acolhida de qualquer funcionário, independente da orientação sexual que ele tenha. O entrevistado 2 afirma que: "[...] eles se importam com produtividade, se você entrega as coisas, essa parte de ser gay ou não nem conta, eu acho... eles deixam essa parte com a gente, não se metem não". Isso confirma que as 
empresas em que os entrevistados trabalham tem foco em características de desempenho do empregado, não realizando distinções por conta de orientações sexuais.

A respeito das ações que as empresas adotam para minimizar esses impactos de diversidade sexual, tem-se relatos desde procedimentos simples, até campanhas bem estruturadas, como indica o entrevistado 2:

[...] a instituição sempre nos permitiu isso, sempre promoveu debates sobre isso, mandava e-mails de orientações... de que o respeito é sempre em primeiro lugar e recentemente eles fizeram um portas abertas alí, abriram pra quem quis ir...quem queria participar pôde? contribuir... portas abertas relacionados a diversidades, que foi com o nosso diretor em São Paulo.

Ademais, o entrevistado 5 admite que a sua orientação sexual o ajuda em suas atividades na empresa: "como eu lido muito com relacionamento de pessoas, com empregados, diretoria e clientes... eu acredito que isso facilita...que nós homossexuais temos mais abertura, facilidade que de repente um heterossexual teria ou não teria?”.

Isso indica uma preocupação da inclusão da diversidade nas organizações, como exposto por Torres \& Pérez Nebra (2004) e Irigaray \& Freitas (2011). Os primeiros autores afirmam que a consideração da diversidade nas organizações significa a inclusão de todos os empregados, independentemente de suas diferenças, etnia, raça, gênero, orientação sexual, idade, entre outros, tentativa que foi observada nas empresas investigadas. A partir da inclusão, é possível evidenciar as diferenças e semelhanças dos empregados e canalizar essas características para contribuir para o desempenho organizacional, motivação e satisfação dos empregados.

Mesmo reconhecendo que as instituições como um todo possuem boas políticas de inclusão e um clima organizacional favorável para a acolhida de empregados homoafetivos, alguns empregados trouxeram à tona questões mais particulares, como gerentes homofóbicos. Os relatos dos entrevistados 3 e 10, respectivamente, indicam essa situação: “[...] tinha um gerente homofóbico que não abria oportunidades pra mim de jeito nenhum. Eu via as oportunidades, via pessoas que chegaram depois de mim crescerem, e eu nada [...]"; "Sim, quando era estagiário a gerente não queria me efetivar porque eu era gay, ela não falava na minha cara, mas ela falava para outros funcionários e eu ficava sabendo [...]”. Assim, percebeu-se que esses empregados quando se deparam com uma liderança mais conservadora têm seu crescimento impedido, uma vez que, esses gestores passam a negar oportunidades aos mesmos. Isso confirma o exposto por Moraes (2004) de que, quando o indivíduo ingressa na 
empresa, ele leva consigo condutas e posturas, tornando-se um ponto de diversidade dentro do trabalho. Observou-se, a partir das entrevistas realizadas, que essa diferença pode acarretar em situações de exclusão, conforme se observou no relato dos entrevistados.

Outra contribuição de Moraes (2004) é a constatação da forma com que essas diversidades se apresentam dentro da organização, geralmente acontecendo nas áreas que possibilitam ocorrência de estreitamento dos relacionamentos internos, entre áreas, intra áreas e nos grupos de trabalho. Nessa perspectiva, alguns entrevistados trouxeram à tona situações e particularidades que variam de departamento para departamento. Por exemplo, o entrevistado 8 afirmou que: “[...] temos departamentos mais heterossexuais, [...] que os caras não perdoam e acabam sendo um pouco preconceituosos, mas no meu departamento, [...] temos a cultura de sempre incluir, independentemente da situação em quem esse funcionário se encontra".

Dessa forma, em relação ao entendimento dos entrevistados sobre a questão da diversidade sexual dentro das instituições financeiras, constatou-se que, apesar de casos isolados de preconceito, as empresas fazem esforços para promover companhas de inclusão e aceitação de empregados homoafetivos. Observou-se que, além dos empregados perceberem essas ações, elas têm boa efetividade de resultados, uma vez que os entrevistados demonstraram se sentirem confortáveis e produtivos nas instituições privadas em que trabalham.

\subsection{Ocorrência de heteronormatividade/heterossexismo e relação com casos de homofobia}

Nessa fase percebeu-se certa confusão por parte dos empregados em afirmarem que trabalham em uma empresa inclusiva e, ao mesmo tempo, de ainda acontecerem determinados casos de heteronormatividade, heterossexismo ou até de homofobia, de maneira isolada ali dentro.

Partindo do conceito de Borillo (2010), a respeito da heteronormatividade - sistema a partir do qual a sociedade organiza determinados tratamentos segregacionistas com base no padrão heterossexual - destaca-se o relato do empregado 5 sobre uma gerente que supervisionou uma agência que ele trabalhou. Ela afirmava que: “[...] para as áreas de atendimento ao cliente, preciso que os empregados sejam mais 'hominhos', sem esses jeitos". O empregado 6 reforça essa ideia de manter algumas condutas heteronormativas em cargos diretamente ligados ao atendimento de clientes e adverte que: "[...] quanto mais afeminado você for, pior vai ser”. Esse conceito se prova, também, na entrevista do empregado 5 que 
afirmou: "[...] conheço muitos empregados homossexuais que não se assumem por medo de não serem aceitos ou de serem julgados".

Esses tipos de atitudes foram observadas como as principais formas de ocorrência de padrões heteronormativos e heterossexistas, por meio de uma super valorização do estereótipo de comportamento heterossexual. Percebe-se que esses depoimentos corroboram a teoria de Herek (1992) ao afirmar que, através do heterossexismo, acontece uma negação das formas não heterossexuais.

Souza e Pereira (2013) afirmam que esse mesmo sistema ideológico produz privilégios para pessoas que seguem as normas heterossexuais e exclui aquelas que não as seguem. Observa-se que, por unanimidade, têm-se preocupações em não ser afeminado demais dentro das instituições financeiras. $\mathrm{O}$ entrevistado 1, que foi o mais afeminado entrevistado na amostra, está há 7 anos na mesma função, o entrevistado 3, por sua vez, no mesmo período já ascendeu 6 vezes de cargo e foi o empregado mais discreto entrevistado na amostra, ou seja, aparentemente ele não tem características diferente de um heterossexual.

Por outro lado, os empregados 1 e 4 destacam que, com a chegada da geração Y (ou Millennials) a essas instituições, houve toda uma movimentação - natural e espontânea - no intuito de adaptar toda a estrutura para a acolhida desses empregados. Isso facilita para que uma grande maioria desses empregados homoafetivos seja assumida e para que os outros empregados sejam mais tolerantes com os empregados mais afeminados.

No que se refere a ocorrência da homofobia nessas empresas, os dados obtidos com as entrevistas mostram que, dentre os 10 empregados participantes, 3 afirmaram sofrer ou já terem sofrido situações homofóbicas de maneira direta e 2 afirmam ter sofrido de maneira indireta, através de piadas e sarcasmo. O entrevistado 4 não só afirma ter sofrido com situações homofóbicas, como relatou um caso em que outro empregado tentou “curá-lo”: “[...] Ela inclusive disse que meia hora com ela resolvia meu problema. Que era só eu deixar ela me pegar de jeito". Associada a essa ideia, temos a constatação de que 4 entrevistados afirmam ter presenciado algum tipo de situação evolvendo a sexualidade de algum empregado, muitas vezes, por meio de brincadeiras ou comentários maldosos feitos "pelas costas" do outro empregado.

Bicalho (2008) indica tais formas de violência como homofóbicas, caracterizando-as como um ato de agressão do sujeito de maneira discursiva em seu ambiente de trabalho. Assim, constatou-se que as colocações de Siqueira \& Fellows (2006) ainda são válidas nos dias atuais, ou seja, por ser uma minoria dentro da sociedade e das organizações, os homossexuais encontram limitações dentro das empresas em que estão inseridos. Estes 
autores afirmam que a homoafetividade constatada (ou admitida) é tema constante de piadas e de desprezo no contexto organizacional onde, consequentemente, o gay assumido é vítima de diversos tipos de violência e boicotes, especialmente quando ocupa posições altas dentro da hierarquia de cargos. Percebe-se, portanto, que a homofobia é algo negativo, gera discriminação e consequente insatisfação para aqueles que são afetados por essa prática.

Com isso, percebe-se que todo o esforço que as instituições fazem através de suas campanhas de conscientização e aceitação de empregados homoafetivos, apresentado no tópico acima, é legitimo e necessário, pois foi observada a ocorrência de situações onde a heteronormatividade/heterossexismo evoluiu para situações homofóbicas de maneira direta e indireta. Destaca-se que as novas gerações (Y e futuras) aparentemente necessitam de um esforço menor para a criação de uma consciência inclusiva e respeitosa, o que poderia ser uma futura linha de pesquisa.

\subsection{Satisfação para funcionários homoafetivos dentro das instituições financeiras}

Segundo Locke (1969), a satisfação no trabalho é resultado da avaliação do próprio empregado sobre o seu trabalho, o que gera uma emoção positiva de bem-estar. Com as entrevistas aplicadas, 8 dos entrevistados declararam-se satisfeitos, em contrapartida com apenas 2 que se declararam insatisfeitos.

Dentre os 8 empregados satisfeitos, 3 declaram estarem satisfeitos, porém não atribuem relação entre satisfação no trabalho com a orientação sexual, e sim devido as suas habilidades pessoais, práticas internas incentivadas pela empresa e, até mesmo, ao departamento em que se encontram hoje, seguindo a proposta de significação proposta por Locke (1969).

Seguindo a lógica de Fraser (1983) - que a satisfação no trabalho é um estado pessoal, subjetivo, dinâmico e constantemente modificável por condições intrínsecas e extrínsecas do trabalho e do trabalhador - tem-se o entrevistado 8 traçando paralelos entre departamentos mais ou menos inclusivos: "[...]Eu sei que se eu mudasse de departamento eu poderia não estar tão satisfeito, mas como a empresa tem diversas políticas inclusivas pra gente...tem até um congresso, fórum, sei lá, sobre isso, que divulgaram pro Brasil todo (apenas empregados) participarem [...] e a gente sabe que não é tanta diferença, é só que tem departamentos que são mais "machão", sabe?!" (Entrevistado 8).

Rego (2001) diz que a satisfação no trabalho está relacionada ao tratamento de justiça e de respeito a que o trabalhador é submetido. Nessa linha de pensamento, a satisfação do 
empregado 10 se justifica: "[...] aqui já estou tranquilo, estou muito satisfeito. Já sei como as coisas funcionam e eu já sei o que posso ou não fazer para eu mesmo não sofrer. Aqui não tenho mais medo de ser demitido por isso, por ser homossexual".

Para Estefano (1996), os fatores considerados como os mais significantes ao estresse e à insatisfação no trabalho são a falta de conhecimento sobre oportunidades de progresso e promoção no trabalho e o modo como ocorre a avaliação da performance profissional. Em conformidade com Estefano (1996) temos 2 empregados insatisfeitos - 1 e 3 -porém destacam não ter relação com a sua orientação sexual e sim com processos de adaptação e falta de ascendência de cargo: “[...] Não, não estou, mas acho que futuramente eu posso estar, tenho muitos planos e ainda estou em adaptação com o novo cargo, mas acho que não tem relação não” (Entrevistado 3); “Ah, faz muito tempo já que estou fazendo as mesmas coisas (7 anos na mesma função).

Assim, destaca-se que os empregados, em sua maioria, estão satisfeitos com seus ambientes de trabalho e que relacionam essa satisfação com a sua aceitação sexual no ambiente de trabalho. Destaca-se que da mesma forma que existem empregados satisfeitos, identificamos empregados insatisfeitos, e também encontramos empregados que não relacionam a sua sexualidade com sua satisfação ou insatisfação.

\section{Considerações Finais}

A realização desta pesquisa permitiu a compreensão de como se encontram as instituições financeiras investigadas no que se refere a satisfação e aceitação/receptividade dos empregados homoafetivos.

No que se refere ao entendimento dos entrevistados sobre a questão da diversidade sexual dentro das instituições financeiras, foi identificado um cenário bem receptivo, com ações e processos internos criados especificamente para a aceitação de empregados homoafetivos. Porém, não se descartam os casos, a princípio isolados, de agências e empregados menos receptivos.

Sobre a identificação se a ocorrência de heteronormatividade/heterossexismo contribui para a ocorrência de casos de homofobia, observou-se a existência de heteronormatividade e heterossexismo de maneira indireta, ou seja, com empregados e em departamentos isolados. Alguns desses casos evoluíram para homofobia, no entanto, destaca-se que sempre em desconformidade aos padrões e políticas estabelecidos pela instituição financeira.

É certo que a heteronormatividade como causa de homofobia ainda precisa ser 
(CC BY 4.0) | ISSN 2525-3409 | DOI: http://dx.doi.org/10.33448/rsd-v9i7.4024

amplamente discutida nas instituições. Faz-se necessário para que o tema se torne cada vez mais público, mais relevante para discussão e para que as organizações o compreendam e se engajem cada vez mais. Esse engajamento pode ocorrer não apenas na intenção de criar processos e ações de conscientização com seus empregados, mas com um foco claro em evitar que o assédio moral e outras formas de agressão aconteçam dentro de suas fronteiras, a partir do seu corpo de empregados.

Sobre averiguar se os funcionários homossexuais se encontram satisfeitos dentro das instituições financeiras, a partir das entrevistas, constatou-se que os empregados, em sua maioria, encontram-se satisfeitos e correlacionam essa satisfação a liberdade de poderem assumir sua sexualidade dentro e fora da instituição sem sofrer qualquer repreensão no ambiente de trabalho. Destacou-se também uma correlação da satisfação com a idade dos empregados no ambiente de trabalho, que é cada vez mais jovem, facilitando a aceitação dos empregados homoafetivos. Por fim, identificamos que o departamento que o empregado se encontra também é um fator determinante para a sua satisfação, tanto pela cultura organizacional própria que diferentes departamentos possuem quanto pelo estilo de liderança dos gestores.

Sugere-se, portanto, que futuras pesquisas busquem abranger empregadas do sexo feminino e homossexuais que também trabalhem em instituições financeiras. Ainda, não apenas de instituições financeiras, mas também empregados de outros segmentos mais conservadores, como empresas ligadas a produção rural ou industrial. Investigar a aceitação de homossexuais em diferentes gerações ( $\mathrm{X}, \mathrm{Y}$ e $\mathrm{Z}$ ) também pode ser válido para compreender os fatores influenciadores e possíveis perspectivas de atuação. É importante destacar também que os homossexuais são apenas um dos grupos que necessitam de pesquisa para identificação de limitações de adaptação. Deve-se também realizar estudos envolvendo outras minorias que possuem baixa visibilidade nas pesquisas sobre a ocorrência de heteronormatividade/heterossexismo, como acontece com os transexuais, por exemplo

\section{Referências}

Alves, M., \& Galeão-Silva, L. (2004). A crítica da gestão da diversidade nas organizações. RAE-Revista de Administração de Empresas, 44(3), 20-29.

Bainha, A., \& Silva, F. A. (2016). Homofobia nas organizações e a legislação aplicada. Revista Borges: estudos contemporâneos em Ciências Sociais e Aplicadas, 6(1), 50-69. 
Baldin, N., \& Munhoz, E. M. B. (2011). Snow Ball (Bola de Neve): uma técnica metodológica para pesquisa em educação ambiental comunitária. In Congresso Nacional de Educação (EDUCERE), X, 2011. Anais... Curitiba.

Bardin, L. (2011). Análise de Conteúdo. São Paulo: Edições 70.

Bicalho, R. A. (2008). Categorias frankfurteanas para uma tipologia da violência nas organizações. In Encontro de estudos organizacionais, 5, 2008, Belo Horizonte. Anais... Belo Horizonte: ANPAD.

Borillo. D. (2010). Homofobia: história e critica de um preconceito. Belo Horizonte: Autentica.

Butler, J. (2008). Problemas de gênero: feminismo e subversão da identidade. ed. 2. Rio de Janeiro: Civilização brasileira.

Carvalho, MEP. (2004). Modos de educação, gênero e relações escola-família. Cadernos de pesquisa, 34(1121), 41-58.

Chaui, M. (1984). Repressão sexual: essa nossa (des)conhecida. São Paulo: brasiliense.

Croteau. J. (1996). Research on the work experience of lesbian, gay and bissexual people: an integrative review of methodology and findings. Journal of vocational behavior, 48(2), 195209.

Davis, K \& Newstrom, JW. (2001). Comportamento Humano no Trabalho: Uma abordagem Organizacional. São Paulo: Pioneira Thomson Learning.

Dourlen, M. (2005). Sentimento de humilhação e modos de defesa do eu. Narcisismo, masoquismo, fanatismo. In I. Marson, \& M. Naxara (Orgs.). Sobre a humilhação: sentimentos, gestos, palavras. Uberlândia: EDUFU. 
Estefano, EVV. (1996). Satisfação dos recursos humanos no trabalho: um estudo de caso na biblioteca central da Universidade Federal de Santa Catarina (Dissertação de Mestrado). Programa do Centro tecnológico de Florianópolis, Universidade Federal de Santa Catarina, Florianópolis.

Facchini, R. (2005). Sopa de letrinhas? Um movimento homossexual e produção de identidades coletivas nos anos 90. Rio de Janeiro: Garamong.

Fleury. MTL. (2000). Gerenciando a diversidade cultural: experiência de empresas brasileiras. Revista de administração de empresas, 4(3), 18-25, 2000.

Fraser, TM. (1983). Human stress, work and job satisfaction: a critical approach. German: International Labour Office.

Freire, L \& Cardinali, D. (2012). O ódio atrás das grades: da construção social da discriminação por orientação sexual a discriminação da homofobia. Sex., Salud Soc. (Rio J.) [online], 12, 37-63.

Gil, AC. (1999). Métodos e técnicas de pesquisa social. 5. ed. São Paulo: Atlas.

Hanashiro, DMM \& Carvalho, SG. (2005). Diversidade cultural: panorama atual e reflexões para a realidade brasileira. $R E A d, 11(5), 1-21$.

Herek, GM. (1992). Confronting sexual stigma and prejudice: theory and pratice. Journal of Social, 63(4), 905-925.

Hirigoyen, M-F. (2006). Mal-estar no trabalho: redefinindo o assédio moral. 3. ed. Rio de Janeiro: Bertrand Brasil.

Irigaray, HAR \& Freitas, ME. (2011). Sexualidade e Organizações: estudo sobre lésbicas no ambiente de trabalho. $O \& S, 18(59), 625-641$.

Junqueira, RD. (2007). Homofobia: limites e possibilidades de um conceito em meio a disputas. Bagoas, 1(1), 145-165. 
Locke, EA. (1969). What is job satisfaction? Organizational Behaviour Human Performance, 4(4), 309-336.

Louro, GL. (2004). Mulheres na sala de aula. In M. Del Priore (Org.). História das mulheres no Brasil (pp. 443-481). 7. ed. São Paulo: Contexto.

Martinez, MC \& Paraguay, AIBB. (2003). Satisfação e saúde no trabalho - aspectos conceituais e metodológicos. Cadernos de Psicologia social do trabalho, 6, 59-78.

Moraes, CV. (2004). A diversidade nas organizações e o indivíduo. Recuperado em http://www.guiarh.com.br/PAGINA22T.html

Nascimento, MAF. (2011). Improváveis relações: produção de sentidos sobre o masculino no contexto de amizade entre homens homo e heterossexuais (Tese de doutorado). Universidade do Estado do Rio de Janeiro, Rio de Janeiro.

Oliveira, CL. (2008). Um apanhado teórico-conceitual sobre a pesquisa qualitativa: tipos, técnicas e características. Travessias - pesquisas em educação, cultura, linguagem e arte, 2(3), 1-16.

Pereira, AS, Shitsuka, DM, Parreira, FJ \& Shitsuka, R. (2018). Metodologia da pesquisa científica. [e-book]. Santa Maria. Ed. UAB/NTE/UFSM. Disponível em: https://repositorio.ufsm.br/bitstream/handle/1/15824/Lic_Computacao_MetodologiaPesquisa-Cientifica.pdf?sequence $=1$.

Rego, A. (2001). Percepções de justiça: estudos de dimencionalização com professores do ensino superior. Psic.: Teor. e Pesq, 17(2), 119-131.

Ribeiro, EA. (2008). A perspectiva da entrevista na investigação qualitativa. Evidência: olhares e pesquisa em saberes educacionais, 4, 29-148.

Robbins, SP. (2002). Comportamento organizacional. 9. ed. São Paulo: Prentice Hall. 
Seffner, F. (2013). Sigam-me os bons: apuros e aflições nos enfrentamentos ao regime da heteronormatividade no espaço escolar. Educação e Pesquisa, 39(1), 145-159.

Scott, J. (1995). Gênero: uma categoria útil de análise histórica. Revista Educação \& Realidade, 20(2), 71-99.

Siqueira, MVS, Saraiva, LAS, Carrieri, AP, Lima, HKB \& Andrade, AJA. (2009). Homofobia e violência moral no trabalho no distrito federal. Organizações \& Sociedade, 16(50), 447-461.

Souza, EM \& Pereira, SJN. (2013). (Re)produção do heterossexismo e da heteronormatividade nas relações de trabalho: a discriminação do homossexual por homossexuais. RAM., 14(4), 76-105.

Smith, NG \& Ingram, KM. (2004). Workplace heterosexism and adjustment among lesbian, gay and bisexual individuals: the rule of unsupportive social interactions. Journal of Counseling Psychology, 51(1), 57-67.

Torres, CV \& Perez Nebra, AR. (2004). Diversidade cultural no contexto organizacional. In Zanelli, JC, Andrade, JEB \& Bastos, AVB. (Orgs.) Psicologia, organizações e Trabalho no Brasil. Porto Alegre: Artmed.

Thomas, RR. (1991). Beyond race and gender: unleashing the power of your total work force by managing diversity. New York: Amacom, 1991.

Vergara, SC. (2011). Projetos e relatórios de pesquisa em administração. 13. ed. São Paulo: Atlas.

Welzer-Lang, DA (2001). Construção do masculino: dominação das mulheres e homofobia. Revista Estudos Feministas, 9(2), 460-481.

Zauli-Fellows, A \& Siqueira, MVS. (2006). Diversidade e Identidade Gay nas Organizações. GESTÃO.Org - Revista Eletrônica de Gestão Organizacional, 4(3), 69-81. 
Research, Society and Development, v. 9, n. 7, e469974024, 2020

(CC BY 4.0) | ISSN 2525-3409 | DOI: http://dx.doi.org/10.33448/rsd-v9i7.4024

\section{Porcentagem de contribuição de cada autor no manuscrito}

Ana Camila Fechio - 40\%

Cleiciele Albuquerque Augusto - 30\%

Thiago Soares Nunes $-30 \%$ 